\title{
Viscosity Study to Optimize a Slurry of Alumina Mixed with Hollow Microspheres
}

\author{
Syed Zaighum Abbas Bukhari****, Jang-Hoon Ha*, Jongman Lee*, and In-Hyuck Song****; \\ *Powder and Ceramics Division, Korea Institute of Materials Science, Changwon 51508, Korea \\ **Korea University of Science \& Technology, Daejeon 34113, Korea
}

(Received August 7, 2015; Revised October 8, October 16, 2015; Accepted October 16, 2015)

\begin{abstract}
Porous alumina ceramics are involved in many industrial applications due to the exceptional properties of these products. This study addresses the preparation of porous alumina ceramics using hollow microspheres as a pore-forming agent and slip casting as a green-body-forming technique. A uniform distribution of pores is a basic requirement of a porous material. This study investigates three different slurry systems, i.e., as-prepared alumina slurry, alumina slurry electrostatically dispersed by hydrochloric acid $(\mathrm{HCl})$, and slurry dispersed by the commercial dispersant 'Darvan C-N'. At a low viscosity, the hollow microspheres in the slurry tend to float, which causes a non-uniform pore distribution. To avoid this phenomenon, the viscosity of the slurry was increased to the extent that the movement of hollow microspheres ceased in the slurry. As a result, a uniform pore distribution was achieved.
\end{abstract}

Key words : Porous materials, Alumina, Slip casting, Viscosity

\section{Introduction}

$\mathrm{T}$ he importance of porous ceramics has recently been recognized due to high levels of demand for such materials in the areas of catalysis, ${ }^{1)}$ separation, ${ }^{2)}$ lightweight structural materials, ${ }^{3)}$ and biomaterials. ${ }^{4)}$ This new interest is due to the unique properties that these materials offer, such as a high melting point, strong corrosion resistance, high wear resistance, low density levels, low thermal conductivities, and low dielectric constants. ${ }^{5}$

Various processing techniques have been utilized to fabricate porous ceramic materials. The representative processes for creating macro-porous ceramics are partial sintering (powder compacts are sintered at lower temperatures or for a shorter time than normal sintering to obtain densified materials), ${ }^{6}$ the use of sacrificial fugitives (a templating material is initially homogenously distributed in a continuous matrix of a ceramic phase and thereafter removed to result in a porous material), ${ }^{7)}$ the use of replica templates (a process in which templates such as polymeric foams are soaked in a ceramic slurry and the surplus is drained off, followed by the burning of the organic components at slow heating rates before sintering), ${ }^{7}$ and direct foaming (a process in which bubbles are incorporated into a ceramic suspension containing surfactant and particles; upon drying and sintering the mixture produces a porous ceramic material). ${ }^{7)}$

${ }^{\dagger}$ Corresponding author : In-Hyuck Song

E-mail : sih1654@kims.re.kr

Tel : +82-55-280-3534 Fax : +82-55-280-3392
In the sacrificial template method, porous ceramics can be obtained by mixing appropriate amounts of sacrificial fugitives as pore-forming agents with ceramic raw powder and evaporating or burning these fugitives out before or during sintering to create pores. Pore-forming agents are generally classified as types of synthetic organic matter (e.g., polymer beads, organic fibers, hollow microspheres), natural organic matter (e.g., potato starch, cellulose, cotton), or liquids (e.g., water, gel, emulsions). ${ }^{8)}$ Templating materials of different sizes, shapes, and arrangements can be used to help to tailor the porosity, pore-size distribution, and pore morphology. However, the removal of the organic templating material can be very time-consuming and may also induce stress and thus cause cracking and deformation of the material. ${ }^{9)}$

Expanded hollow microspheres are one option for use as a sacrificial fugitive for the fabrication of porous ceramics. These are low-density micron-sized spherical thermoplastic particles that consist of a polymeric shell encapsulating a gas. Given their very low density when burning, less dense gases evolve, thus reducing the potential for crack formation. $^{10)}$

To create a green body of a porous ceramic material, the slip-casting technique was used. Forming by means of casting is an important process that has been used in traditional and modern ceramic production. It is a process in which a slip, i.e., a creamy mixture consisting of solids suspended in a liquid, such as water, is poured into a porous mold, in which the surplus liquid is absorbed and a solid replica of the inside of the mold is obtained. The rheological properties of slip-casting are of importance because they are among the significant parameters that control the produc- 
tion characteristics. The rheological properties depend on the physical and chemical properties of the raw material and on the conditions under which the slip-casting is prepared. The viscosity of the slip depends on the particle size, the shape and type of the raw material, the viscosity of the medium, the mixing speed, and the purity of the water used.

When using slip-casting as a means of creating a green body, a slurry formation is initially required. If a ceramic slurry with low viscosity is mixed with hollow microspheres, the hollow microspheres tend to float due to their very low density, leading to severe pore segregation. ${ }^{11)}$ In order to overcome this problem, in this study we sought to optimize the slurry condition to determine the relationship between the slurry viscosity and the distribution of the pores in a porous, sintered alumina ceramic.

\section{Experimental Procedure}

High-purity $\mathrm{a}-\mathrm{Al}_{2} \mathrm{O}_{3}$ powder (assay 99.995\%), AP-400, purchased from POS-HiAL, Korea, was used for the preparation of the slurries. The median particle size $\left(\mathrm{D}_{50}\right)$ of the powder ranged from 0.3 to $0.5 \mu \mathrm{m}$, the packed bulk density ranged from 0.7 to $0.9 \mathrm{~g} / \mathrm{cm}^{3}$, and the BET surface area was $6 \sim 10 \mathrm{~m}^{2} / \mathrm{g}$. The crystal morphology of a-alumina can be clearly observed in the SEM image of the powdered sample shown in Fig. 1. In addition, the average size of the powder was $<0.5 \mu \mathrm{m}$. When introducing the spherical pores into the hollow microspheres of the alumina cast samples (Expancel Microspheres 092-DET 80-d25 purchased from Akzo Nobel Pulp and Performance Chemicals AB Expancel, Sweden) as a sacrificial polymer template, the median particle size $\left(\mathrm{D}_{50}\right)$ was $80 \mu \mathrm{m}$ and the true density was $0.025 \pm 0.003 \mathrm{~g} / \mathrm{cm}^{3}$, as provided by the supplier. Distilled water was used throughout the study as a solvent to create the slurries, while $\mathrm{HCl}$ and aqueous $\mathrm{NaOH}$ were used to maintain the $\mathrm{pH}$. In addition, an ammonium poly-methacrylate aqueous solution, Darvan C-N (M/S, R.T. Vanderbilt Co. Norwalk, CT, USA) with a molecular weight $(\mathrm{Mw})$ in a range of approximately 10,000 to 16,000 and with $25 \pm 1.0 \%$ of solids, completely soluble in water, was used as a dispersant for the alumina slurries.

To measure the viscosity and casting of the alumina slips, three types of slurries were created. These were slurries

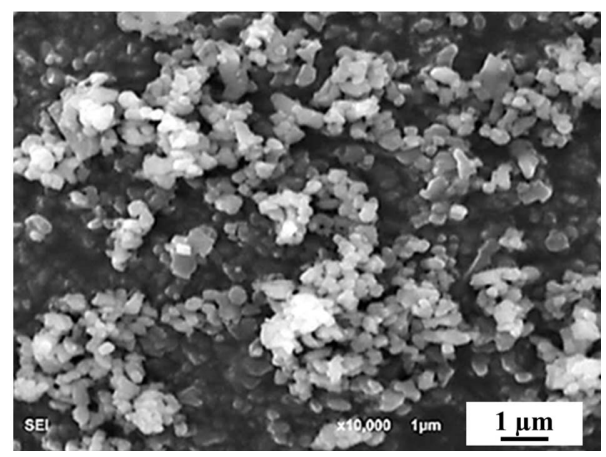

Fig. 1. SEM of the AP-400 alumina powder. with only alumina powder and distilled water; slurries which contained alumina powder, distilled water, and $\mathrm{HCl}$ ( $\mathrm{HCl}$ was added to maintain the $\mathrm{pH}$ of the slurries at $4.5^{ \pm}$ 0.3 ); and slurries of alumina powder, distilled water, and the dispersant Darvan C-N. After calculating the quantities based on the vol.\% of the solid, the mixtures were mixed in plastic bottles and ball-milled using alumina balls $(10 \mathrm{~mm}$ in diameter). The ratio of alumina powder to alumina ceramic balls was set at $1: 2$. The milling process, operated at $200 \mathrm{rpm}$, lasted for $5 \mathrm{~h}$. Slurries with $10 \%$ and $15 \%$ solid loading rates without the addition of a dispersant, slurries of alumina with a pH adjustment at $40 \%$ and $50 \%$ solid loading rates, and slurries of alumina with the addition of a dispersant at $50 \%$ and $55 \%$ solid loading rates were mixed with 50 vol.\% of hollow microspheres in a properly covered beaker using a magnetic stirrer for 30 minutes (while gradually increasing the stirring rate from $200 \mathrm{rpm}$ to $1000 \mathrm{rpm}$ ) to disperse the entire quantity of the hollow microspheres in the slurries separately. Slip-casting (using pre-dried gypsum molds) was conducted by decanting the slurries mixed with the hollow microspheres into a mold; this was followed by drying overnight at room temperature in the mold. The cast material was then separated from the mold and dried in a hot air oven at $60^{\circ} \mathrm{C}$ for $4 \mathrm{~h}$. After the samples were dried, they were sintered at $1600^{\circ} \mathrm{C}$ with a dwell time of $2 \mathrm{~h}$. The overall process is shown schematically in Fig. 2.

The $\mathrm{pH}$ of the alumina slurries was measured using a $\mathrm{pH}$ meter (Mettler Toledo, InLab ${ }^{\circledR}$ Expert Pro, USA): the viscosity measurements were conducted using a Brookfield DV-II+ Pro (Brookfield Engineering Laboratories, Inc., USA) viscometer with a CPE-40 spindle. The microstructures of the cross-sections of the specimens (after polishing with 200 to 2000 grit $\mathrm{SiC}$ paper) were observed using a scanning electron microscope (JSM-5800, JEOL, Tokyo, Japan).

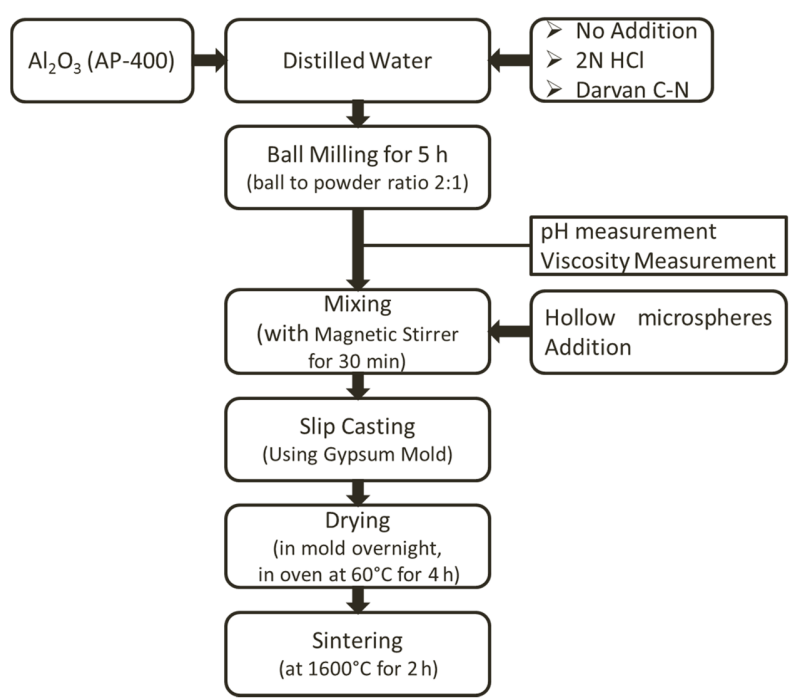

Fig. 2. Flow chart showing procedure for the fabrication of the porous $\mathrm{Al}_{2} \mathrm{O}_{3}$ ceramic. 


\section{Results and Discussion}

Slip-casting involves the use of stabilized slurries of high solid loading rate. This process was evaluated by varying the composition of liquid (i.e., distilled water, distilled water $+\mathrm{HCl}$, and distilled water + dispersant and amount of alumina powder). Several studies of ceramic powder have been conducted to demonstrate that ceramic powder retains its non-Newtonian characteristics (i.e., its viscosity changes with a change in the shear rate). In this study, which used sub-micron sized alumina powder, all slurries showed shear-thinning behavior (i.e., a reduction in the apparent viscosity with an increase in the shear rate) irrespective of the slurry solid content or the type of dispersant added. The viscosity data used in this study were determined at a shear rate of $750 \mathrm{~s}^{-1}$. Therefore, each time the term viscosity is used, the viscosity of the slurry is assumed to have been measured at a shear rate of $750 \mathrm{~s}^{-1}$.

\subsection{Alumina slurry with/without hollow micro- spheres (no additional treatment)}

Initially, the slurries were made while adding water to alumina powder using different solid ratios on a vol.\% basis to find the maximum possible solid loading rate. Fig. 3 shows that with an increase in the solid loading rate, the viscosity of the slurries increased. The rate of $30 \mathrm{vol} \%$ of solid loading was found to be the maximum achievable solid loading rate for creating the slurries. When this value was exceeded, slurry formation did not occur.

The addition of hollow microspheres increased the viscosity of the slurry. At solid loading rates of 20 vol.\% and above, without the addition of a dispersant, the flowability of the slurry reached its minimum; when the hollow micro-

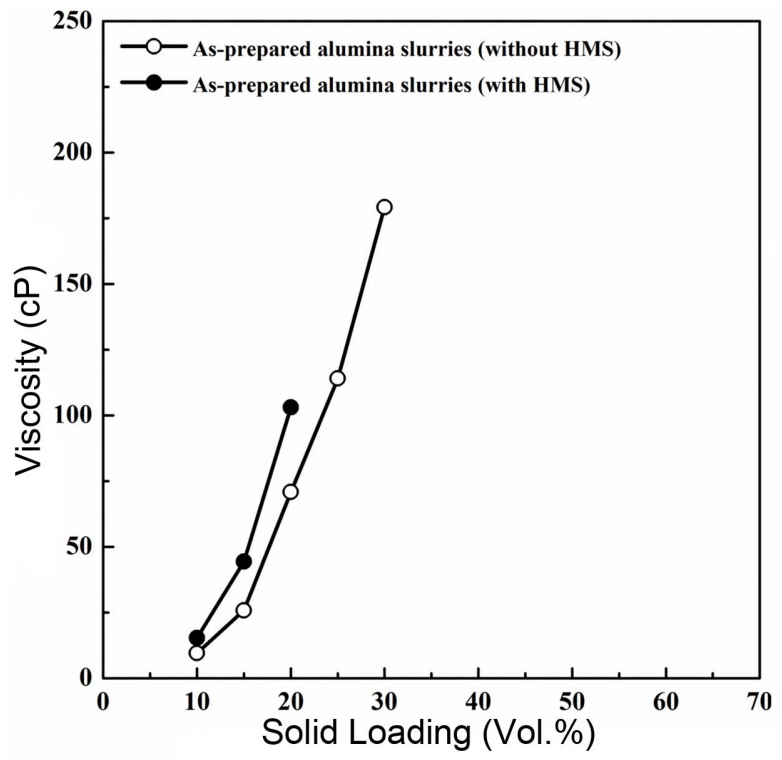

Fig. 3. Effect of solid loading on the viscosity of the suspension without addition of a dispersant at a shear rate of $750 \mathrm{~s}^{-1}$ spheres were added to the slurry, the slurry lost its flow characteristics and only a thick paste was observed. The maximum solid loading needed to create an alumina slurry without the addition of a dispersant was found to be 30 vol.\%. At solid loading rates of $20 \mathrm{vol} . \%$ and below, the mixing of hollow microspheres was possible, with some flow characteristics as well. When the slurry was casted into a gypsum mold, with the casted material then sintered to observe the microstructure, it was revealed that for a slurry with a solid loading rate of $10 \mathrm{vol} . \%$, a non-uniform pore distribution arose (Fig. 4(a)). When the solid loading rate was increased to 15 vol.\% (Fig. 4(b)), a uniform distribution of the pores was observed. These two samples also showed that there is a transition state between the solid loading rates of 10 vol.\% (viscosity $15.43 \mathrm{cP}$ ) and 15 vol.\% (viscosity $44.47 \mathrm{cP}$ ). Thus, to obtain a porous alumina ceramic material with a uniform distribution of pores, the loading rate of the slurry solid should be 15 vol. $\%$ or higher.

\subsection{Alumina slurry with/without hollow micro- spheres, dispersed by $\mathrm{pH}$ adjustment}

As in an earlier case, the optimized solid loading rate was found to be very low. Therefore, the slurries were optimized by changing the $\mathrm{pH} .{ }^{12}$ This phenomenon was studied in an effort to disperse the alumina slurry electrostatically. Surface charges in oxides are mainly derived from the preferential dissolution or deposition of ions. Ions adsorbed onto the solid surface determine the surface charge and are thus
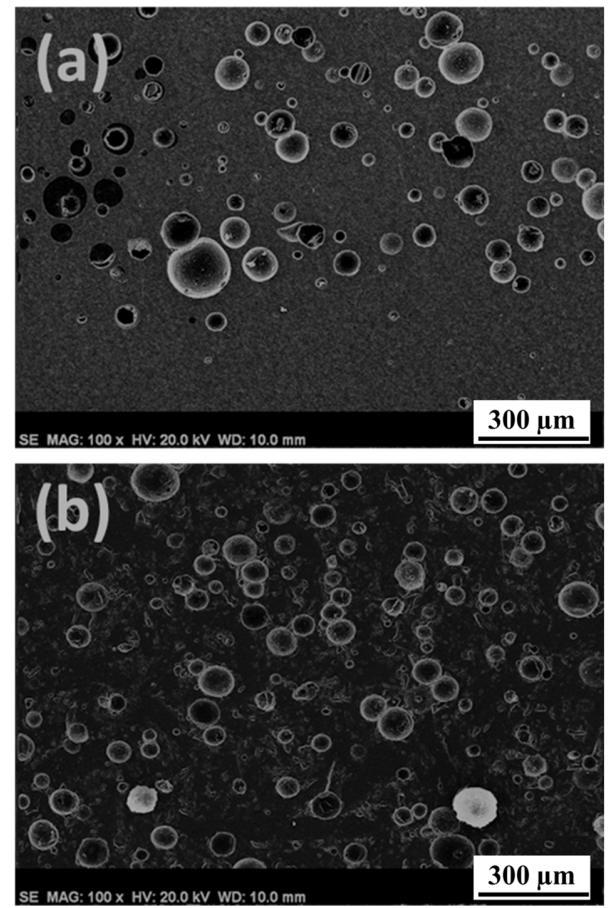

Fig. 4. Typical SEM images of alumina with hollow microspheres without the addition of a dispersant, sintered for $2 \mathrm{~h}$ at $1600^{\circ} \mathrm{C}$ with (a) 10 vol.\% of solid loading and (b) 15 vol.\% of solid loading. 
referred to as charge-determining ions. In oxide systems, typical charge-determining ions are protons and hydroxyl groups; their concentrations are described in terms of their $\mathrm{pH}\left(\mathrm{pH}=-\log \left[\mathrm{H}^{+}\right]\right)$. As the concentration of the chargedetermining ions varies, the surface charge density changes from positive to negative, or vice versa. The concentration of charge-determining ions corresponding to a neutral or zerocharged surface is defined as the point of zero charge, or the isoelectric point (IEP). When the $\mathrm{pH}$ exceeds the IEP, the oxide surface is negatively charged, as the surface is covered with hydroxyl groups (OH-), an electrical-determining ion. When the $\mathrm{pH}$ is less than the IEP, hydrogen ions $(\mathrm{H}+)$ are the charge-determining ions and the surface is positively charged. Thus, the more specific the charge on the surface of the oxide, the greater the repulsion will be between the particles of the oxide.

To evaluate the abovementioned effect, alumina slurries of 25 vol.\% with different $\mathrm{pH}$ levels were formulated using $\mathrm{HCl}$ and $\mathrm{NaOH}$. The $\mathrm{pH}$ of the slurry without any further addition was found to be 7.65, as shown in Fig. 5. It was also noted that at $\mathrm{pH}$ levels below 5.6 and above 10.5, the slurry reaches the point of minimum viscosity. The viscosity was also found to reach its maximum at $\mathrm{pH}$ levels ranging from 8.25 to 9.25 due to the fact that, at these values, there is the highest possibility of reaching the isoelectric point (IEP), which is close to the IEP previously reported for alumina suspensions. ${ }^{13)}$ Thus, to ensure that the slurries are fully dispersed, the $\mathrm{pH}$ level for further study and for the preparation of the slurry was set at $4.5 \pm 0.3$, which is well below the IEP of the alumina slurry.

The changes in the viscosity with increases in the solid loading rate for slurries adjusted to a $\mathrm{pH}$ at $4.5 \pm 0.3$ are shown in Fig. 6, which shows that the possible solid loading

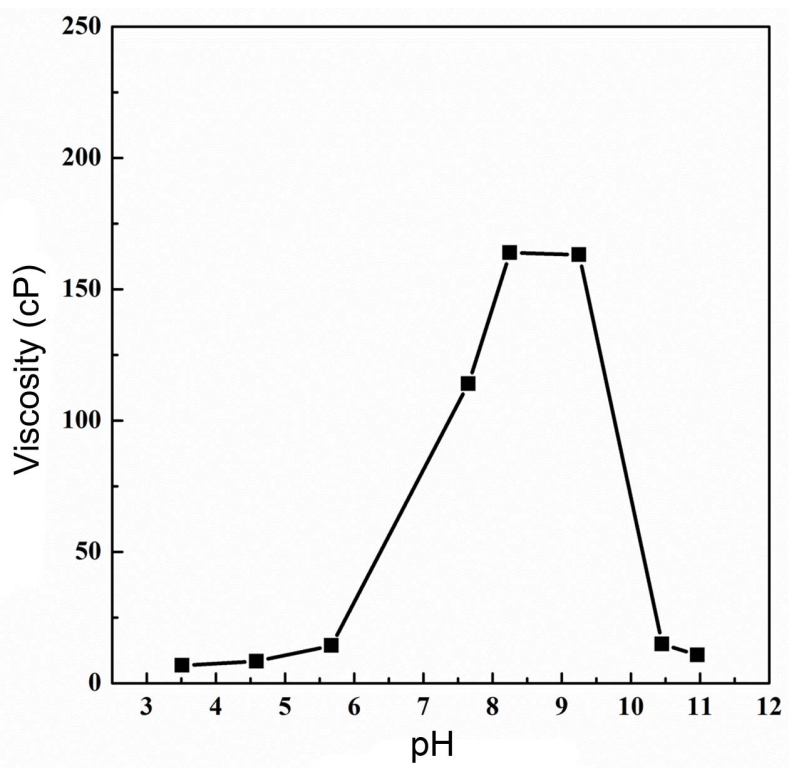

Fig. 5. Effect of $\mathrm{pH}$ change on 25 vol.\% alumina slurry viscosity at shear rate of $750 \mathrm{~s}^{-1}$. rate with only $\mathrm{pH}$ change was found to be as high as 60 vol.\%. It was also observed that the mixing of hollow microspheres tends to increase the slurry viscosity, as mentioned earlier. At a solid loading rate of $60 \mathrm{vol} \%$, the slurry viscosity was high, such that the viscosity was out of the measuring range of the instrument (Fig. 6). At 50 vol.\% and below, slurries with sufficient flow properties formed. When these slurries were tested to observe the behavior of the hollow microspheres in the slurries by casting the slurries with hollow microspheres, it was found, according to the microstructure, that, at solid loading rates of 50 vol.\% (Fig. 7(b)) and above, the slurry viscosity was so high that the movement of the hollow microspheres in the upward direction was completely halted and a homogeneous distribution of pores was observed. At a solid loading rate of less than $40 \mathrm{vol} . \%$, a severe non-uniform pore distribution was observed (Fig. 7(a)). It was also noted that smaller pores were on the lower side and larger pores were on top. This occurred due to the buoyant force of the large hollow microspheres, and vice-versa.

\subsection{Alumina slurry with/without hollow micro- spheres, dispersed by dispersant}

The use of Darvan C-N as a dispersant is very common when the dispersion of an alumina slurry is required. ${ }^{14-16)}$ Darvan C-N is an ammonium polymethacrylate aqueous solution that can dissociate in water, providing negatively charged polymers. Its structure and dissociation reaction, shown below, illustrate that the functional groups are carboxylic acid groups that can be $\mathrm{COOH}$ or can be dissociated to $\mathrm{COO}-{ }^{17)}$

In a study by Singh et al. ${ }^{15)}$ it was shown that Darvan C-N changes the IEP of an alumina slurry from $\mathrm{pH} 9.14$ to $\mathrm{pH}$ 5.65. An addition of Darvan C-N causes a negative charge

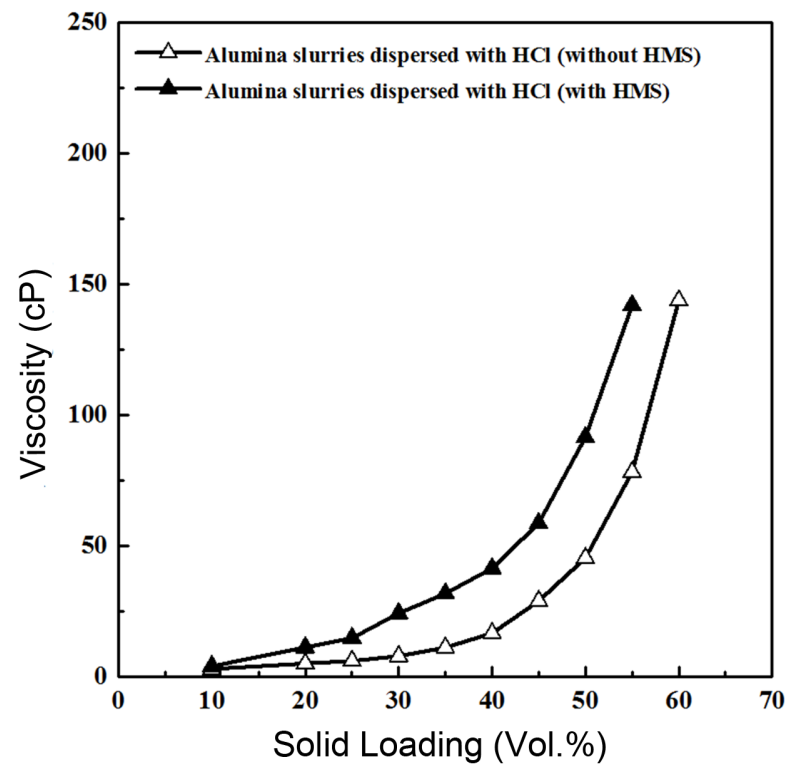

Fig. 6. Effect of solid loading on the viscosity of the suspension dispersed with $\mathrm{HCl}$ at $4.5 \pm 0.3$, at a shear rate of $750 \mathrm{~s}^{-1}$. 

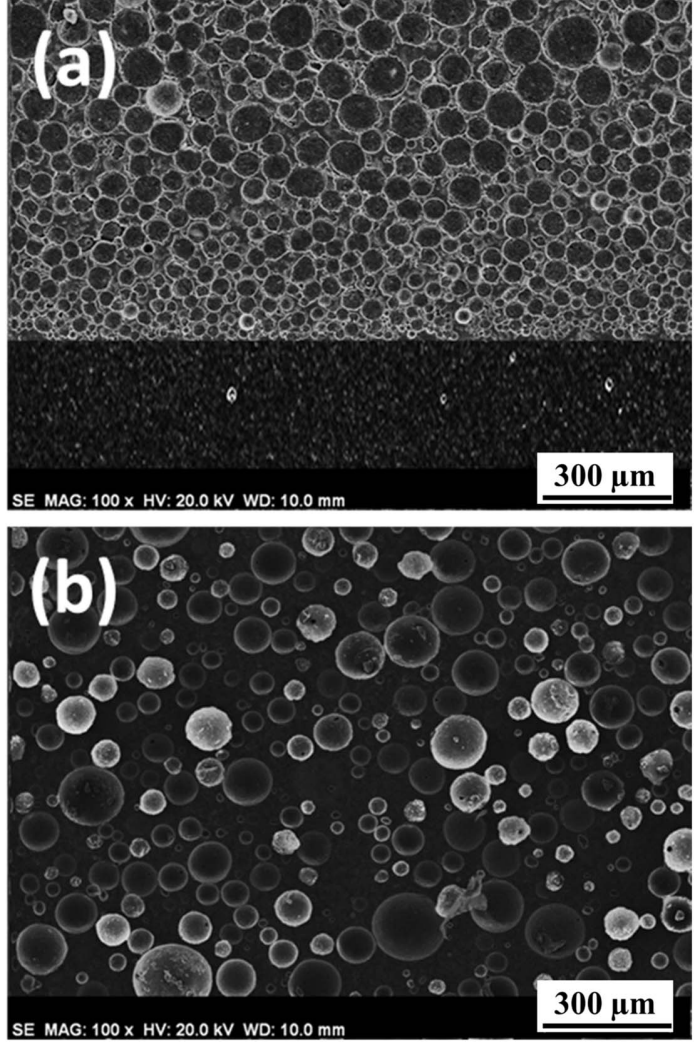

Fig. 7. Typical SEM images of alumina with hollow microspheres dispersed by $\mathrm{pH}$ adjustment and sintered for $2 \mathrm{~h}$ at $1600^{\circ} \mathrm{C}$ with (a) 40 vol.\% of solid loading and (b) 50 vol.\% of solid loading.

on the particle surface at a wide range of $\mathrm{pH}$ levels above 5.65. The change in the IEP of alumina occurs due to the absorbance of the negatively charged carboxylic groups dissociated from Darvan C-N on the positively charged alumina surface via electrostatic attraction. As a result, the particles become more negatively charged. The surface, being more negatively charged, will require more $\mathrm{H}+$ to neutralize the surface charge and hence shifts the IEP to an acidic $\mathrm{pH}$.

To optimize the dispersant concentration, the relationship between the dispersant concentration and the viscosity of the slurry was established. To evaluate this relationship, slurries with solid loading rates of 50 vol.\% were created with various concentrations of the dispersant, ranging from 0.32 to 5.08 wt.\% (based on a polymer solution, which corresponds to 0.08 to 1.27 wt.\% of active matter) of dry alumina powder, as shown in Fig. 8. The optimum dispersant concentration was found to be 0.1 weight $\%$ of active matter, as this value gives the lowest slurry viscosity. At that level, the dispersant is capable of monolayer coverage of the particles. As a result, the particles have high repulsive force and thus high fluidity. ${ }^{18)}$ At a lower concentration of the dispersant, the particles were not completely covered and the development of partial positive and negative charges led to flocculation. On the other hand, at higher concentrations,

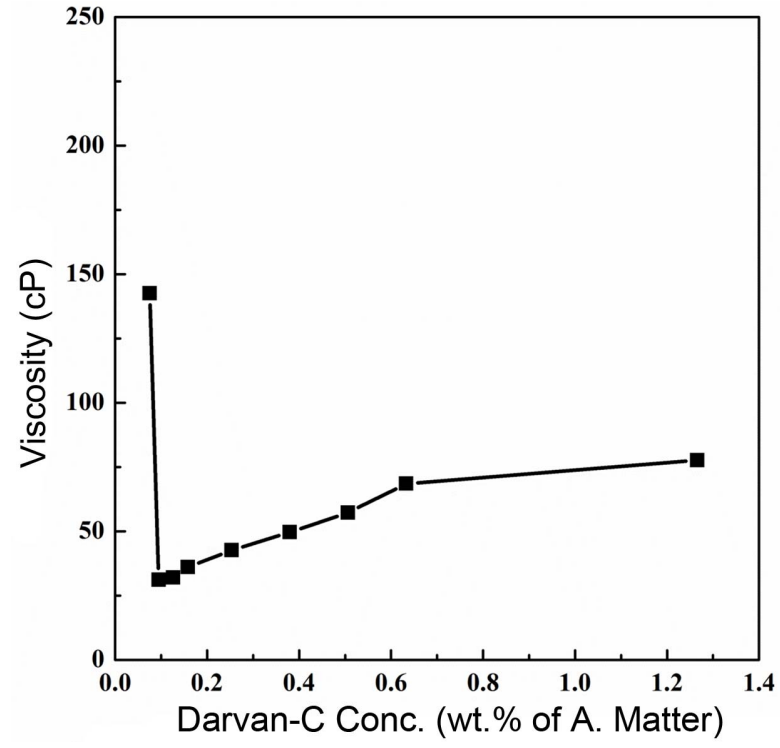

Fig. 8. Effect of the Darvan C-N concentration on the 50 vol.\% alumina slurry viscosity at shear rate of $750 \mathrm{~s}^{-1}$.

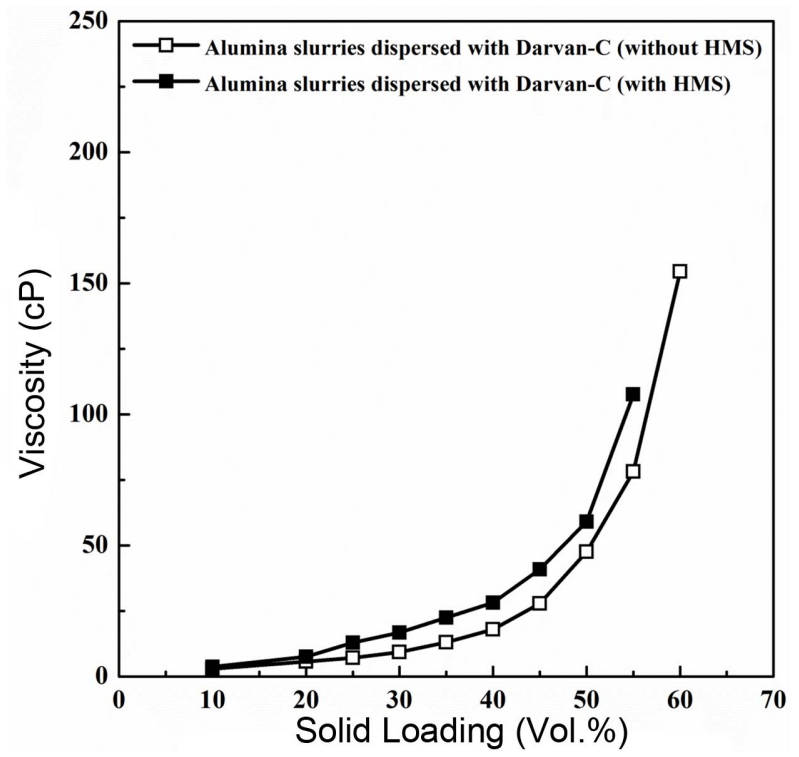

Fig. 9. Effect of solid loading on the viscosity of the suspension dispersed with $0.1 \%$ Darvan $\mathrm{C}-\mathrm{N}$ at shear rate of $750 \mathrm{~s}^{-1}$.

flocculation may occur due to bridging or depletion effects, leading to increased viscosity.

The effect of $0.1 \mathrm{wt} . \%$ of the dispersant on solid loading was determined, as was the effect on the viscosity, as shown in Fig. 9. The $\mathrm{pH}$ of the slurry under this condition was found to be 9.03 , which is well above the IEP of the alumina slurry dispersed by Darvan C-N. The behavior of the alumina slurries was found to be similar to that of the slurries dispersed using $\mathrm{HCl}$. With Darvan C-N as the dispersant, the maximum attainable solid loading rate was 60 vol.\%. However, one difference was that, after the addition of the hollow microspheres, the increase in the viscosity was not 
as high as were those for the slurries dispersed with $\mathrm{HCl}$ as a dispersant. Moreover, hollow microsphere mixing was possible for slurries with solid loading rates of $60 \mathrm{vol} . \%$ and below, with sufficient flowability. At solid loading rates of 55 vol.\% and above, a good distribution of pores was observed in the casted and sintered sample (Fig. 10(a)), while, with solid loading rates of 50 vol.\% and lower, pore segregation was observed (Fig. 10(b)).

It was also observed that in the slurry with a low solid loading rate, hollow microspheres tended to rise to the surface. This occurred because, in a fluid, a lightweight material always moves upward due to variations in the density; moreover, the alumina slurry particles were not rigid enough to stop the upward movement of the hollow microspheres. It was not possible to overcome the problem of the density difference between the powder and the hollow microspheres; instead, it was necessary to increase the slurry viscosity. Therefore, it was observed that slurries with high solid loading rates and high viscosity levels have sufficient ability to resist the upward movement of hollow microspheres, thus maintaining the distribution.

Table 1 provides a summary of the schematic morphology and effects of surface charges for the different slurry conditions. It can be deduced that alumina slurry without any dispersant has a positive surface charge on alumina particles because the IEP of alumina is around $\mathrm{pH} \mathrm{9.} \mathrm{The}$ surface charge was weakly positive because the $\mathrm{pH}$ of the slurry (7.65) is very close to the IEP of alumina. On the other hand, slurries dispersed with $\mathrm{pH}$ adjustment have strong positive surface charges, because the $\mathrm{pH}$ of the slurry (4.5) is in the high positive surface charge range. In the case of Darvan C-N, the IEP of the alumina slurries shifted to 5.65 and the $\mathrm{pH}$ of the slurry changed to 9.03 ; thus, the surface charge of the alumina particles became negatively charged.

It is interesting to observe that when negatively charged
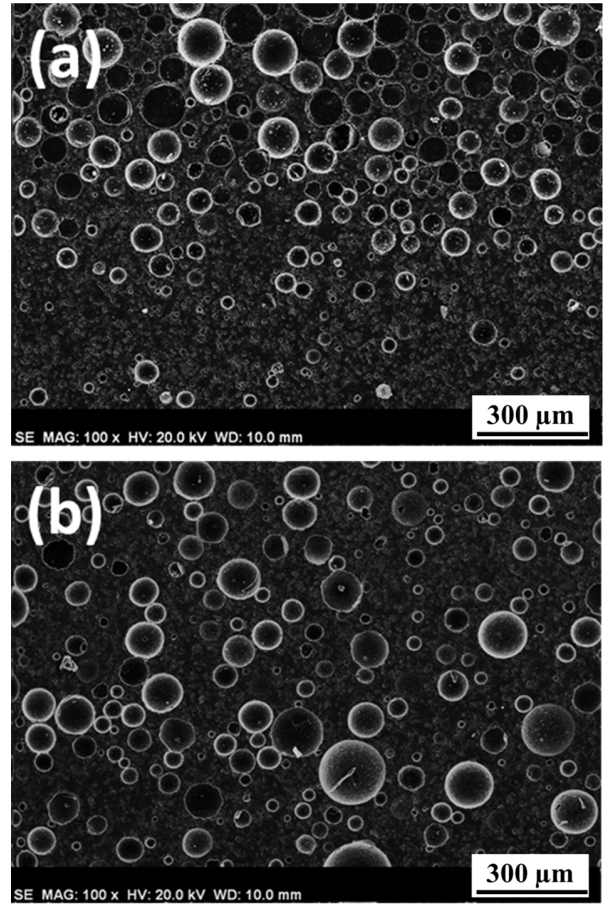

Fig. 10. Typical SEM images of alumina with hollow microspheres dispersed by a dispersant and sintered for $2 \mathrm{~h}$ at $1600{ }^{\circ} \mathrm{C}$ with (a) 50 vol.\% of solid loading and (b) 55 vol.\% of solid loading.

hollow microspheres were added to slurries having positively charged alumina particles, slurry viscosity was increased by the additive effect of the addition of another component and the addition of oppositely charged components. On the other hand, in the case of a slurry with negatively charged alumina particles (slurries dispersed with Darvan C-N), when a mixture with hollow microspheres undergoes only the effect of the addition of another component, due to the same charges, repulsion occurs between the

Table 1. Summary of the Effect of Surface Charge on Different Slurry Conditions

\begin{tabular}{ccc}
\hline Slurry system & Without dispersant & Dispersed by $\mathrm{pH}$ adjustment Dispersed by Darvan C-N \\
\hline Schematic morphology & bad & bad \\
\hline Slurry stability & 7.65 & strong positive \\
\hline Siscosity for homogeneous distribution & $45 \mathrm{cP}$ & $90 \mathrm{cP}$ \\
\hline Working $\mathrm{pH}$ & weakly positive
\end{tabular}


alumina particles and the hollow microspheres, which hinders the viscosity from increasing. And so this can be seen to be the reason that more solid loading or high viscosity is required to achieve homogeneous distribution between alumina particles and hollow microspheres.

\section{Conclusions}

A uniform distribution of pores was successfully achieved by increasing the solid loading rate. The solid loading rate was increased to a level at which the viscosity of the slurry remained sufficiently high to resist the movement of the hollow microspheres that had been put in it. A comparison of slurry viscosities with increases in the solid loading rate for three systems was performed, showing that the slurries dispersed with $\mathrm{HCl}$ and a dispersant had nearly identical behaviors. We can conclude that values of 15 vol.\% solid loading for a slurry without any addition, 50 vol.\% solid loading for slurries dispersed with $\mathrm{HCl}$, and 55 vol.\% solid loading for slurries dispersed with a dispersant can be used to create porous alumina structures with uniform pore distribution. However, the best combination is a slurry with the highest solid loading rate, i.e., 55 vol.\%, with the slurry dispersed with Darvan C-N as a dispersant. It is evident from the microstructures that by mixing hollow microspheres with alumina, it is possible to create a porous alumina ceramic material with closed pores. Closed pores, due to their dense pore walls, help in the creation of thermal and acoustic shielding materials.

\section{Acknowledgments}

This study was supported financially by the Research Program of the Korea Institute of Materials Science (KIMS).

\section{REFERENCES}

1. C. Cybulski and J. A. Moulijna, "Monoliths in Heterogeneous Catalysis," Cat. Rev. Sc. Eng., 36 [2] 179-270 (1994).

2. E. J. Granite and T. O'Brien, "Review of Novel Methods for Carbon Dioxide Separation from Flue and Fuel Gases," Fuel Proc. Tech., 48 [14] 1423-34 (2005).

3. A. Okada, "Automotive and Industrial Applications of Structural Ceramics in Japan," J. Eur. Ceram. Soc., 28 [5] 1097-4 (2008).

4. C. Piconi and G. Maccauro, "Zirconia as a Ceramic Biomaterial," Biomaterials, 20 [1] 1-25 (1999).

5. K. Ishizaki, S. Komarneni, and M. Nanko, Porous Materi- als; Vol. 4, pp. 1-5, Springer-Science \& Business Media, Germany, 1998.

6. Y. Imanaka, Multilayered Low Temperature Cofired Ceramics (LTCC) Technology; pp. 21-58, Springer Science \& Business Media, Germany, 2005.

7. T. Ohji and M. Fukushima, "Macro-porous Ceramics: Processing and Properties," Int. Mat. Rev., 57 [2] 115-31 (2012).

8. P. Colombo, "Conventional and Novel Processing Methods for Cellular Ceramics," Phil. Trans. R. Soc. A, 364 [1838] 109-24 (2006).

9. H. Wang, X. Li, J. Yub, and D. Kim, "Fabrication and Characterization of Ordered Macroporous PMS-derived SiC from a Sacrificial Template Method," J. Mater. Chem., 14 [9] 1383-86 (2004).

10. J. Eom, Y. Kim, I. H. Song, and H. D. Kim, "Processing and Properties of Polysiloxane-derived Porous Silicon Carbide Ceramics Using Hollow Microspheres as Templates," J. Eur. Ceram. Soc., 28 [5] 1029-35 (2008).

11. J. Andertová, J. Havrda, and R. Tláskal, "Preparation of Functionally Graded Alumina Ceramic Materials with Controlled Porosity," Stud. Surf. Sci. and Cat., 160 629-37 (2007).

12. D. J. Kim, H. Kim, and J. K. Lee, "Dependence of the Rheological Behavior of Electrostatically Stabilized Alumina Slurries on pH and Solid Loading;" J. Mater. Sci., 33 [11] 2931-35 (1998).

13. P. Singh, R. Menchavez, C. Takai, M. Fuji, and M. Takahashi, "Stability of Dispersions of Colloidal Alumina Particles in Aqueous Suspensions," J. Coll. Inter Sci., 291 [1] 181-86 (2005).

14. A. Tsetsekou, C. Agrafiotis, and A. Milias, "Optimization of the Rheological Properties of Alumina Slurries for Ceramic Processing Applications, Part I: Slip-casting," J. Eur. Ceram. Soc., 21 [3] 363-73 (2001).

15. P. Singh, S. Bhattacharjee, L. Besra, and D. K. Sengupta, "Evaluation of Dispersibility of Aqueous Alumina Suspension in Presence of Darvan C," Ceram Int., 30 [6] 936-46 (2004).

16. R. M. Anklekar, S. A. Borkar, S. Bhattacharjee, C. H. Page, and A. K. Chatterjee, "Rheology of Concentrated Alumina Suspension to Improve the Milling Output in Production of High Purity Alumina Powder," Colloids Surf. A., 133 [1-2] 41-7 (1998).

17. T. Fengqiu, H. Xiaoxian, Z. Yufeng, and G. Jingkun, "Effect of Dispersants on Surface Chemical Properties of Nano-zirconia Suspensions," Ceram Int., 26 [5] 93-7 (2000).

18. R. Greenwood and L. Bergström, "Electroacoustic and Rheological Properties of Aqueous Ce-ZrO $\mathrm{Zr}_{2}(\mathrm{Ce}-\mathrm{TZP})$ Suspensions," J. Eur. Ceram. Soc., 17 [4] 537-48 (1997). 